\title{
Study of the distribution of temperatures in the windings of a transformer after suffering a short-circuit.
}

\author{
I. Fernández ${ }^{1}$, J. Carcedo ${ }^{1}$, F. Ortiz ${ }^{1}$, F. Delgado ${ }^{1}$, A. Ortiz ${ }^{1}$, A. Arroyo ${ }^{1}$ \\ ${ }^{1}$ Department of Electrical Engineering \\ E.T.S.I.I., Cantabria University \\ Avenida de los Castros, 39005 Santander (Spain) \\ Phone/Fax number:+0034 942200932, e-mail: inmaculada.fernandez@unican.es
}

\begin{abstract}
Power transformers are electrical machines that allow us to transport electric energy, with reduced losses, from generation stations to consumption points. This definition gives us an idea of the number of machines of this type that are used in power distribution systems worldwide. The lifespan of this equipment often exceeds 30 years of operation. Therefore, they can be described as very robust equipment. The main problem that may affect power transformers is the operation at high temperature. This paper summarizes the results of a post mortem study carried out on an 800 kVA distribution transformer. The methodology that is considered for estimating the temperature distribution in the windings of the machine is based on the calculation of the degree of polymerization of the dielectric paper. This parameter is associated with the state of the paper insulation that protects the conductors of the windings. By knowing the value of this magnitude for a new and for an aged paper, and the period of operation of a transformer, the temperature distribution along the height of the windings can be estimated. With these results and the loading regime that a transformer has endured throughout his life, one can draw conclusions for future designs or for similar transformers still in operation.
\end{abstract}

\section{Key words}

Kraft paper, Degree of polymerisation, Activation energy.

\section{Introduction}

Transformers are one of the most expensive and critical components of electric energy transmission and generation systems [1]. Although transformers are very reliable machines a failure is possible at any age due to many factors as incorrect specification or operation, design or manufacturing errors, bad maintenance, excessive ageing...[2]. Therefore knowing transformers condition is essential to the asset management of large networks [3].

The transformers' life span is determined amongst other parameters by the condition of the solid insulation, particularly at the hot spot [4]. The primary insulation used in liquid filled power transformers is cellulose [6]. The cellulose which is composed of polymerized glucose molecules suffers degradation due to thermal stress caused by electric load losses in the transformer, moisture, oxygen, contamination from conducting particles and mechanical damage or weakening from vibration [5]. The three main processes for cellulose degradation are hydrolysis, oxidation, and pyrolysis [6]. Hydrolysis involves water and acids, which break the cellulose polymer chain. Oxygen dissolved in the oil accelerates the rate of aging of paper. Pyrolysis is decomposition occurring at temperatures above $140^{\circ} \mathrm{C}$. Transformer paper operating under normal or overload conditions does not reach this temperature unless a fault develops. The products of cellulose degradation are carbon monoxide (CO), carbon dioxide (CO2), organic acids, water and free glucose molecules. The glucose rings can decompose further into furans [7].

These degradation by-products are soluble in transformer oil. For this reason, analysis of the oil for the degradation by-products (water, dissolved gases, furans) have been used to determine the degree of aging of the cellulose insulation [8]. Nevertheless, these techniques are macro in respect to the entire insulation system where may exist a significant thermal gradient [4]. The hot-spot temperature is one of the most critical parameter to estimate the remaining lifetime of solid insulation $[2,3]$. This temperature can be estimated trough thermal model of a transformer taking into account the loading profile of the system, the ambient temperature profile over the year and the setting of the thermostatically controlled cooling system [9]. Other method to determine this hot-spot temperature is taking paper samples from representative parts of the windings and analysing for degree of polymerisation (DP) which is a valid indicator of paper ageing with a value of 200 taken as end of life [10]. It measures the average chain length of the cellulose molecules. However, it is not possible to obtain paper samples from a transformer in service. The DP 
determination is only possible when a transformer has been removed from service and a detailed post-mortem investigation of the solid insulation is performed [4].

Different authors have carried out a procedure in which paper samples are taken and tested for DP to obtain a map of the solid insulation aging [3-4, 11-13]. For instance, Koch et al. investigated new approaches to determine water in oil-paper-insulated power transformers to conform diagnostic parameters to post mortem investigations as well as, correlations between the furan (2-FAL) concentration in the oil and the average DP [6, 11]. Their aim was to close the gap between the findings during the visual inspection of the active part just before scrapping, the results of the material analysis and parameters which can easily be measured during the life time of the transformer such as water, dissolved gas analysis (DGA) and furans. Susa et al. carried out the condition assessment of a generator transformer by the mapping of degree of polymerization (DP). They also showed the temperature mapping, where the temperature estimation was based on the paper aging kinetics, transformer loading and insulation operating history. Finally, they gave a new equation for the relative aging rate considering all insulation conditions providing possibility of counting transformer loss-of-life more accurately [3, 13]. Prevost et al. also carried out a forensic analysis because the oil analysis had not yield a clear picture of a possible problem in two transformers [4]. Other situation where accurate paper degradation diagnostic could be useful was described by Martins et al. [12]. At the end of 2007, and after a network rearrangement in a region of Portugal, the Pracana substation became redundant. These authors performed a condition evaluation of a transformer to make a decision regarding its transfer to a new substation located in the same region. They carried out a diagnostic based on oil analysis and measures of DP, comparing both.

The combination of the results from service history and post mortem analysis from scrapped and failed transformers help to discover design and material problems specific to a family of transformers which were designed for a specific application and have the same size, voltage class, winding style and cooling system.

All these post-mortem studies have been based on DP which constitutes one of the most important parameters of the insulation condition. The chain length of the cellulose molecules determines the mechanical strength of insulation with cellulose materials. The mechanical strength of the cellulose fibers weakens continuously due to the cellulose's degradation [14]. This paper has taken paper samples from a failed distribution transformer. From these samples, DP calculations have been performed for the three windings of this machine. The basic aim of this analysis was to correlating DP map with the short-circuit. This approach has not been used for any other authors before.

\section{Transformer description}

The tests were performed with the dielectric paper of a 800kVA three-phase transformer, manufactured in 1986 with an ONAN cooling system. The total weight of the transformer is $2130 \mathrm{~kg}$, with an insulating liquid mass of
$390 \mathrm{~kg}$. The connection of the transformer windings is Dy11 type with a ratio of voltages $30.000 / 400 \mathrm{~V}$. The transformer suffered a short-circuit between turns and it had to be removed from service.

Each coil has a height of $50 \mathrm{~cm}$ and paper samples were taken at different heights in order to calculate DP values. The isolation of the transformer consists of several layers of paper, pressboard and copper. The paper layer uses two strips of kraft paper for insulating windings, one internal and one external. Samples of both types of strips were collected and analysed during the tests in order to see their condition. In Table I are recorded the heights of the points at which paper samples were taken from the windings for further analysis. $e_{1}$ means that the sample belongs to the external paper strip and $e_{2}$ that the sample belongs to the internal paper strip.

\section{Methodology to obtain temperature distribution into the transformer}

Firstly, paper samples have been taken out. The next step has obtained the DP mapping in accordance with ASTM D4243 [15]. Once DP results have been obtained the temperature distribution was estimated through cellulose kinetics. Different authors have reported the relationship between DP, time and temperature [16]. In this work, it has been considered the relationship defined by [17] who suggested that the rate of change of DP can be represented by:

$$
\frac{d D P}{d t}=-k_{1} * D P^{2}
$$

if $\mathrm{k}_{1}$ is constant, this equation can be integrated:

$$
\frac{1}{D P_{0}}-\frac{1}{D P_{t}}=k_{1} * t
$$

However, if $\mathrm{k}_{1}$ changes with the time:

$$
\frac{d k_{1}}{d t}=-k_{2} * k_{1}
$$

where $\mathrm{k}_{2}$ is constant. Integrating and rearranging:

$$
\begin{aligned}
& \int_{0}^{t} \frac{d k_{1}}{k_{1}}=\int_{0}^{t}-k_{2} * d t \\
& k_{1_{t}}=k_{1_{0}} * e^{-k_{2} * t}
\end{aligned}
$$

Substituting into equation 1 :

$$
\begin{aligned}
& \frac{d D P_{t}}{d t}=-D P_{t}^{2} * k_{1_{0}} * e^{-k_{2} *_{t}} \\
& \int \frac{d D P_{t}}{D P_{t}^{2}}=\int-k_{1_{0}} * e^{-k_{2} *^{*}} * d t \\
& -\left[\frac{1}{D P}\right]_{D P_{0}}^{D P_{t}}=\left[\frac{k_{1_{0}}}{k_{2}} * e^{-k_{2} *_{t}}\right]_{0}^{t} \\
& -\frac{1}{D P_{t}}+\frac{1}{D P_{0}}=\frac{k_{1_{0}}}{k_{2}} *\left[e^{-k_{2} * t}-1\right] \\
& \frac{1}{D P_{t}}-\frac{1}{D P_{0}}=\frac{k_{1_{0}}}{k_{2}} *\left[1-e^{-k_{2} * t}\right]
\end{aligned}
$$

where $\mathrm{k}_{10}$ is the initial rate at which bonds break, $\mathrm{k}_{2}$ is the rate at which $\mathrm{k}_{10}$ changes, $\mathrm{DP}_{\mathrm{t}}$ is the insulation $\mathrm{DP}$ value 
at time $\mathrm{t}, \mathrm{DP}_{0}$ is the initial insulation $\mathrm{DP}$ value and $\mathrm{t}$ is the time in hours.

Assuming that the Arrhenius equation is valid over the temperature range used in the experiments done by [32], the authors have extrapolated this expression to a lower value corresponding with the average operating temperature in power transformers. The Arrhenius equation can be expressed:

$$
k=A^{*} e^{-\frac{E_{a}}{R^{*} T}}
$$

where $\mathrm{k}$ : rate constant

$$
\begin{aligned}
& \text { A: pre-exponential factor } \\
& \mathrm{E}_{\mathrm{a}} \text { : activation energy } \\
& \mathrm{R} \text { : molar gas constant (8.314 JK-1mol-1) } \\
& \mathrm{T} \text { : temperature in Kelvin }
\end{aligned}
$$

The optimised activation energies and preexponential factors for Kraft paper aged in oil obtained through laboratory experiments [32] are:

Table I. - Arrhenius parameters for Kraft paper in oil.

\begin{tabular}{|c|c|c|}
\hline & $\mathbf{E}_{\mathbf{a}}(\mathbf{J} / \mathbf{m o l})$ & $\mathbf{A}\left(\mathbf{h}^{\mathbf{- 1}}\right)$ \\
\hline $\mathrm{k}_{10}$ & 115200 & $9.10^{*} 10^{8}$ \\
\hline $\mathrm{k}_{2}$ & 126900 & $3.06 * 10^{12}$ \\
\hline
\end{tabular}

In order to estimate the distribution temperatures it has been assumed that the $\mathrm{DP}_{0}$ value was 1257 . It has been estimated that the transformer was run for 227760 hours so, $t=227760 h$. Finally, $\mathrm{DP}_{\mathrm{t}}$ values were obtained following the steps explained previously.

Once the temperature distributions are obtained for the three windings, the final step is to compare them in order to find out any cause of the short-circuit between turns.

\section{Results}

The summary of the results obtained are shown in Table I. The details of the calculations and measurements made are not given here because the space necessary would be larger than that available for articles in this conference.

As shown in this table, DP values range from 276.9 to 364.4. If these DP values are plotted as a function of height, differentiating each of the coils and also whether it is an external or internal layer, the figures 1, 2 and 3 can be obtained.

By observing these figures it is found that there is the same aging along the entire height of the coil. It is also observed that the deterioration of paper is similar in both the inner and the outer layer, although overall deterioration of the inner layer is slightly higher than the one of the outer layer.

The DP map allows us to estimate the existing temperature distribution in the transformer during operation, Table II, which is also a valuable tool for estimating the remaining life in similar transformers that work under the same load conditions, from the point of view of paper state.

The temperature profile shows that the maximum temperature inside the transformer is $357.7 \mathrm{~K}$. Considering this maximum temperature, which represents the most unfavorable conditions, it is possible to estimate the life of others transformers with similar characteristics and operating conditions. By using Eq. 6 and taking into account that the transformer reaches its end of life when the DP of the paper presents a value around 200. In order to calculate the remaining life of the transformer, the time can be obtained from Eq. 5:

\begin{tabular}{|c|c|c|c|c|}
\hline Sample & $\begin{array}{l}\text { Height } \\
(\mathrm{cm})\end{array}$ & Coil & $\begin{array}{c}\text { Outer layer (e1), } \\
\text { inner layer (e2) }\end{array}$ & $\begin{array}{c}\text { Degree of } \\
\text { polymerization }\end{array}$ \\
\hline 1 & 50 & 3 & e1_1 & 309.37 \\
\hline 2 & 50 & 3 & e2_1 & 286.69 \\
\hline 3 & 40 & 3 & e1_2 & 282.40 \\
\hline 4 & 40 & 3 & e2_2 & 325.81 \\
\hline 5 & 30 & 3 & e1_3 & 290.40 \\
\hline 6 & 30 & 3 & e2_3 & 288.15 \\
\hline 7 & 19 & 3 & e1_4 & 276.93 \\
\hline 8 & 19 & 3 & e2_4 & 307.33 \\
\hline 9 & 10 & 3 & e1_5 & 316.60 \\
\hline 10 & 10 & 3 & e2_5 & 313.86 \\
\hline 11 & 2 & 3 & e1_6 & 277.93 \\
\hline 12 & 2 & 3 & e2_6 & 326.80 \\
\hline 13 & 50 & 2 & e1_7 & 298.11 \\
\hline 14 & 50 & 2 & e2_7 & 286.48 \\
\hline 15 & 40 & 2 & e1_8 & 296.90 \\
\hline 16 & 40 & 2 & e2_8 & 297.09 \\
\hline 17 & 30 & 2 & e1_9 & 326.30 \\
\hline 18 & 30 & 2 & e2_9 & 279.70 \\
\hline 19 & 20 & 2 & e1_10 & 301.20 \\
\hline 20 & 20 & 2 & e2_10 & 354.40 \\
\hline 21 & 10 & 2 & e1_11 & 289.77 \\
\hline 22 & 10 & 2 & e2_11 & 297.73 \\
\hline 23 & 0 & 2 & e1_12 & 284.67 \\
\hline 24 & 0 & 2 & e2_12 & 336.80 \\
\hline 25 & 45 & 1 & e1_13 & 363.70 \\
\hline 26 & 45 & 1 & e2_13 & 361.87 \\
\hline 27 & 10 & 1 & e1_14 & 333.73 \\
\hline 28 & 10 & 1 & e2_14 & 364.40 \\
\hline 29 & 5 & 1 & e1_15 & 343.60 \\
\hline 30 & 5 & 1 & e2_15 & 300.53 \\
\hline
\end{tabular}

$$
\begin{aligned}
& k_{1_{0}}=A^{*} e^{\frac{-E_{a}}{R^{* T}}}=9,1 * 10^{8} * e^{\frac{-115200}{8,314 * 357,7}}=1,37 * 10^{-8}\left(h^{-1}\right) \\
& k_{2}=A^{*} e^{\frac{-E_{a}}{R^{* T}}}=3,06 * 10^{12} * e^{\frac{-126900}{8,314 * 357,7}}=8,99 * 10^{-7}\left(h^{-1}\right) \\
& t \text { (remaining life })=-\frac{1}{k_{2}} * \ln \left(1-\left(\left(\frac{1}{D P_{t_{2}}}-\frac{1}{D P_{t_{1}}}\right) * \frac{k_{2}}{k_{1_{0}}}\right)\right)= \\
& \frac{-1}{8,99 * 10^{-7}} * \ln \left(1-\left(\left(\frac{1}{200}-\frac{1}{276,9}\right) * \frac{8,99 * 10^{-7}}{1,37 * 10^{-8}}\right)\right)
\end{aligned}
$$$$
\mathrm{t}(\text { remaining life })=131400(h)=15(\text { años })
$$

Table I. Determination of Degree of Polymerization (DP).

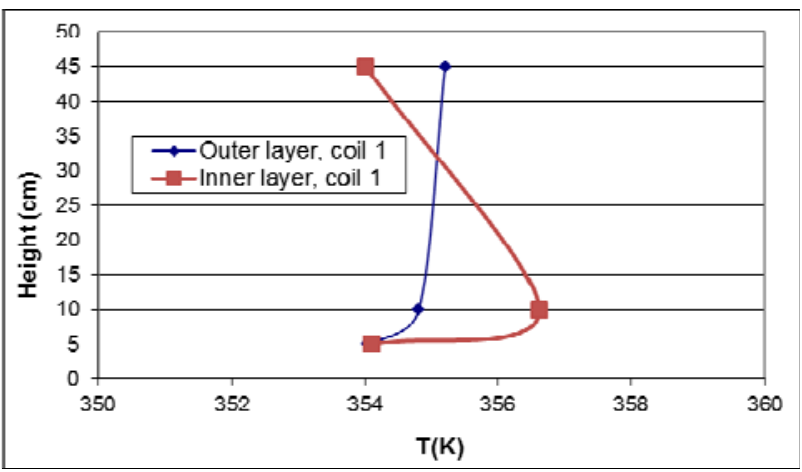

Fig. 1. Temperature distribution in coil1 (it suffered the shortcircuit between turns). 
Table II. Determination of temperature distribution.

\begin{tabular}{|c|c|c|c|c|}
\hline $\mathrm{T}^{\mathrm{a}}(\mathrm{K})$ & $\left(1 / \mathrm{DP}_{\mathrm{t}}\right)-\left(1 / \mathrm{DP}_{0}\right)$ & $\mathrm{k}_{10}\left(9.1 * 10^{8} * \mathrm{e}^{\left(-\mathrm{Ea} / \mathrm{R}^{*} \mathrm{~T}\right)}\right)$ & $\mathrm{k}_{2}\left(3.06 * 10^{12 *} \mathrm{e}^{(-\mathrm{E} / \mathrm{R} / \mathrm{T})}\right)$ & $\left(\mathrm{k}_{10} / \mathrm{k}_{2}\right) *\left(1-\mathrm{e}^{-\mathrm{k} 2 * \mathrm{t}}\right)$ \\
\hline 356.22 & $2.44 * 10^{-3}$ & $1.16^{*} 10^{-8}$ & $7.53 * 10^{-7}$ & $2.44 * 10^{-3}$ \\
\hline 357.24 & $2.69 * 10^{-3}$ & $1.30 * 10^{-8}$ & $8.51 * 10^{-7}$ & $2.69 * 10^{-3}$ \\
\hline 357.44 & $2.75 * 10^{-3}$ & $1.33 * 10^{-8}$ & $8.72 * 10^{-7}$ & $2.75 * 10^{-3}$ \\
\hline 355.53 & $2.27 * 10^{-3}$ & $1.08 * 10^{-8}$ & $6.93 * 10^{-7}$ & $2.27 * 10^{-3}$ \\
\hline 357.07 & $2.65 * 10^{-3}$ & $1.28 * 10^{-8}$ & $8.34 * 10^{-7}$ & $2.65 * 10^{-3}$ \\
\hline 357.17 & $2.68 * 10^{-3}$ & $1.29 * 10^{-8}$ & $8.44 * 10^{-7}$ & $2.68 * 10^{-3}$ \\
\hline 357.70 & $2.82 * 10^{-3}$ & $1.37 * 10^{-8}$ & $8.99 * 10^{-7}$ & $2.82 * 10^{-3}$ \\
\hline 356.31 & $2.46 * 10^{-3}$ & $1.18 * 10^{-8}$ & $7.61 * 10^{-7}$ & $2.46 * 10^{-3}$ \\
\hline 355.91 & $2.36 * 10^{-3}$ & $1.13^{*} 10^{-8}$ & $7.26 * 10^{-7}$ & $2.36 * 10^{-3}$ \\
\hline 356.03 & $2.39 * 10^{-3}$ & $1.14 * 10^{-8}$ & $7.36 * 10^{-7}$ & $2.39 * 10^{-3}$ \\
\hline 357.65 & $2.80 * 10^{-3}$ & $1.36 * 10^{-8}$ & $8.94 * 10^{-7}$ & $2.80 * 10^{-3}$ \\
\hline 355.49 & $2.26 * 10^{-3}$ & $1.07 * 10^{-8}$ & $6.89 * 10^{-7}$ & $2.26 * 10^{-3}$ \\
\hline 356.72 & $2.56 * 10^{-3}$ & $1.23 * 10^{-8}$ & $8.00 * 10^{-7}$ & $2.56 * 10^{-3}$ \\
\hline 357.25 & $2.69 * 10^{-3}$ & $1.30 * 10^{-8}$ & $8.52 * 10^{-7}$ & $2.69 * 10^{-3}$ \\
\hline 356.77 & $2.57 * 10^{-3}$ & $1.24 * 10^{-8}$ & $8.05 * 10^{-7}$ & $2.57 * 10^{-3}$ \\
\hline 356.76 & $2.57 * 10^{-3}$ & $1.24 * 10^{-8}$ & $8.04 * 10^{-7}$ & $2.57 * 10^{-3}$ \\
\hline 355.51 & $2.27 * 10^{-3}$ & $1.08 * 10^{-8}$ & $6.91 * 10^{-7}$ & $2.27 * 10^{-3}$ \\
\hline 357.57 & $2.78 * 10^{-3}$ & $1.35 * 10^{-8}$ & $8.85 * 10^{-7}$ & $2.78 * 10^{-3}$ \\
\hline 356.58 & $2.52 * 10^{-3}$ & $1.21 * 10^{-8}$ & $7.86 * 10^{-7}$ & $2.52 * 10^{-3}$ \\
\hline 354.39 & $2.03 * 10^{-3}$ & $9.52 * 10^{-8}$ & $6.04 * 10^{-7}$ & $2.03 * 10^{-3}$ \\
\hline 357.10 & $2.66 * 10^{-3}$ & $1.28 * 10^{-8}$ & $8.37 * 10^{-7}$ & $2.66 * 10^{-3}$ \\
\hline 356.74 & $2.56 * 10^{-3}$ & $1.23 * 10^{-8}$ & 8.01E-07 & $2.56 * 10^{-3}$ \\
\hline 357.33 & $2.72 * 10^{-3}$ & $1.31 * 10^{-8}$ & $8.61 \mathrm{E}-07$ & $2.72 * 10^{-3}$ \\
\hline 355.08 & $2.17 * 10^{-3}$ & $1.03 * 10^{-8}$ & $6.56 \mathrm{E}-07$ & $2.17 * 10^{-3}$ \\
\hline 355.21 & $2.20 * 10^{-3}$ & $1.04 * 10^{-8}$ & 6.67E-07 & $2.20 * 10^{-3}$ \\
\hline 354.01 & $1.95 * 10^{-3}$ & $9.13 * 10^{-9}$ & $5.76 \mathrm{E}-07$ & $1.95 * 10^{-3}$ \\
\hline 354.81 & $2.11 * 10^{-3}$ & $9.97 * 10^{-9}$ & $6.35 \mathrm{E}-07$ & $2.11 * 10^{-3}$ \\
\hline 356.61 & $2.53 * 10^{-3}$ & $1.21 * 10^{-8}$ & 7.89E-07 & $2.53 * 10^{-3}$ \\
\hline 354.03 & $1.95 * 10^{-3}$ & $9.16 * 10^{-9}$ & $5.78 \mathrm{E}-07$ & $1.95 * 10^{-3}$ \\
\hline 356.13 & $2.41 * 10^{-3}$ & $1.15 * 10^{-8}$ & 7.45E-07 & $2.41 * 10^{-3}$ \\
\hline 354.10 & $1.97 * 10^{-3}$ & $9.22 * 10^{-9}$ & 5.83E-07 & $1.97 * 10^{-3}$ \\
\hline
\end{tabular}

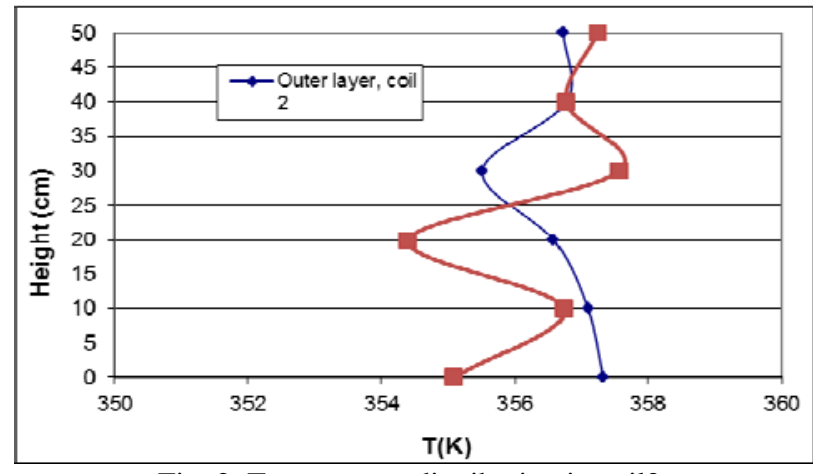

Fig. 2. Temperature distribution in coil2.

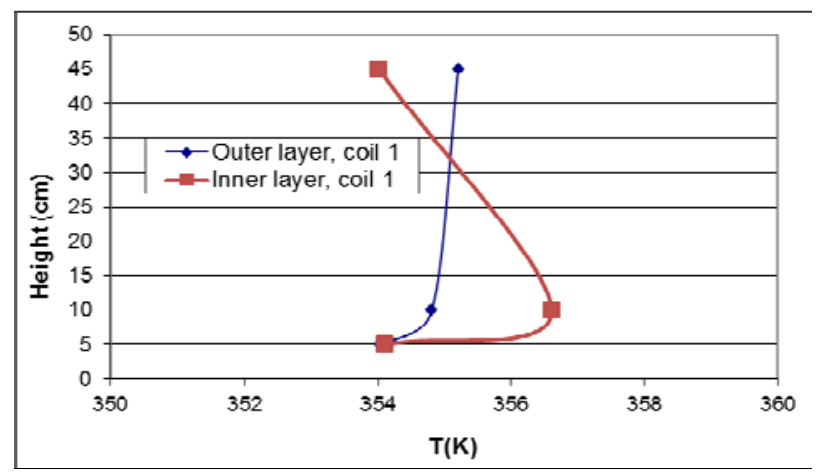

Fig. 3. Temperature distribution in coil3.

\section{Conclusions}

In this paper the authors have tried to predict the occurrence of a short circuit between turns from the state of degradation of paper insulation in the three windings of a distribution transformer. To achieve this goal the degree of polymerization has been used, which is a direct measure of the state of paper. This technique could be useful to predict potential failures caused by paper degradation in other similar transformers still in operation. The control of the insulation degradation in machines in operation could be performed through indirect methods, as it is the concentration of furans in the oil, which can be carried out with the transformer in service. On the contrary, during operation of the machine is not possible to measure DP values.

The results obtained in this work have shown that for this type of machine, commonly used in distribution networks, it is difficult to predict the occurrence of a short-circuit between turns from the state of degradation of kraft paper.

\section{Acknowledgement}

In this section the authors want to acknowledge the great support of a company to the study presented here: General Electric (Factory of Andoain) provided us the distribution transformer and technical help. 


\section{References}

[1] Georgilakis, P.S. Spotlight on Modern Transformer Design. Springer: London, UK, 2009.

[2] P. Jarman, Z.D. Wang, Q. Zhong and T. Ishak, "End-of-life modelling for power transformers in aged power system networks," in CIGRE 2009 6th Southern Africa Regional Conference, Cape Town, Southern Africa, 2009.

[3] D. Susa, K.B. Liland, L. Lundgaard and G. Vardal, Generator step-up transformer post mortem assessment, EUROPEAN TRANSACTIONS ON ELECTRICAL POWER Euro. Trans. Electr. Power 2011;21:1802-1822

[4] Prevost, T.A.; Gasser, H.P.; Krause, C., The value of postmortem investigations for the condition assessment of power transformers, Weidmann-ACTI Inc. Sixth Annual Technical Conference 2007, 1-11.

[5] IEEE Guide for Failure Investigation, Documentation, and Analysis for Power Transformers and Shunt Reactors, 1991.

[6] Postmortem Investigation of Power Transformers - Profile of Degree of Polymerization and Correlation With Furan Concentration in the Oil, Thomas Leibfried, Michael Jaya, Norbert Majer, Michael Schäfer, Manfred Stach und Stephan Voss, IEEE TRANSACTIONS ON POWER DELIVERY, VOL. 28, NO. 2, 2013

[7] C. Homagk, K. Mossner, and T. Leibfried, "Investigation on degradation of power transformer solid insulation material," in 2008 Annual Report Conference on Electrical Insulation Dielectric Phenomena, 2008, pp. 75-78.

[8] Leibfried, T. ; Thieb, U. ; Hohlein, I. ; Breitenbauch, B. ; Lainck, T. ; Leibner, J. ; Truant, S., Profile of water content and degree of polymerisation in the solid insulation of power transformers, IEEE International Symposium on Electrical Insulation, 2004, 109 - 112.
[9] Taghikhani MA, Gholami A. Temperature distribution in ONAN power transformer windings with finite element method. European Transactions on Electrical Power 2009; 19: 718-730.

[10] A.M.Emsley, G.C.Stevens "Review of chemical indicators of degradation of celulosic electrical paper insulation in oilfilled transformers" IEE procedings on Science Measurement and Technology 1994, 141 (5) pp. 324-334.

[11] M. KOCH, S. TENBOHLEN, D. GISELBRECHT, C. HOMAGK, T. LEIBFRIED, Onsite, Online and Post Mortem Insulation Diagnostics at Power Transformers, CIGRÉ, 2007

[12] Martins, M.A. ; Fialho, M. ; Martins, J. ; Soares, M. ; Cristina, M. ; Lopes, R.C. ; Campelo, H.M.R., Power transformer end-of-life assessment-pracana case study* , Electrical Insulation Magazine, IEEE Volume: 27 , Issue: 6 (2011) , 15 - 26

[13] Lelekakis, N. ; Wenyu Guo ; Martin, D. ; Wijaya, J. ; Susa, D. , A field study of aging in paper-oil insulation systems, Electrical Insulation Magazine, IEEE Volume: 28 , Issue: 1, $2012,12-19$

[14] L.E. Lundgaard, W. Hansen, D. Linhjell, and T.J. Painter, "Ageing of oil-impregnated paper in power transformers", IEEE Trans. Dielectr. Electr, Insul., Vol. 19, pp. 230-239, 2004.

[15] ASTM D4243-99(2009) Standard test method for measurement of average viscometric degree of polymerization of new and aged electrical papers and boards.

[16] B. Pahlavanpour, M. Augusta G. Martins, A. De Pablo, Experimental investigation in to the thermal ageing of Kraft paper and mineral insulating oil, ISEI 2002, IEEE International Symposium on Electrical Insulation, 2002, 341-345.

[17] Richard John Heywood, The Degradation Models of Cellulosic Transformer Insulation, Thesis, 1997. 